\title{
A Application of Cloud Computing and IOT in Logistics
}

\author{
Dongxin Lu' ${ }^{1}$, Qi Teng ${ }^{2}$ \\ ${ }^{1}$ Software College, Nanchang University, Nanchang, China; ${ }^{2}$ Software College , Nanchang University, Nanchang, China. \\ Email: lu.dongxin@zte.com.cn; qianxuntq@163.com
}

Received 2012

\begin{abstract}
This paper analyzes the characteristics of cloud computing and IOT (internet of things), introduce a logistics operation based on cloud computing and IOT, which establish a logistics information interchange, data exchange to meet the business requirements of the various types of logistics public information platform.
\end{abstract}

Keywords: Cloud Computing; IOT; Public Information Platform

\section{The logistics}

\subsection{The Definition of Logistics}

Logistics refers to use of modern information technologies and equipment, takes the goods from suppliers to receive accurate, timely, accurate, secure, quality and quantity of rationalization, door to door service mode and service processes.

It is the management of the flow of resources, between the point of origin and the point of destination in order to meet some requirements, for example of customers or corporations. The resources managed in logistics can include physical items as food, materials, equipment, liquids and staff as well as abstract items as information, particles and energy. The logistics of physical items usually involves the integration of information flow, material handling, production, packaging, inventory, transportation, warehousing and oftentimes security. Furthermore the complexity of logistics can be modeled, analyzed, visualized and optimized by dedicated simulation software. Minimizing time and use of resources are common goals. [1]

Logistics appears with the emergence of commodity products, with the development of commodity products, so logistics is an ancient traditional economic activity. However, this traditional logistics system has a big problem, Figure 1 is an example of the traditional logistics model, we can find that between the supplier and the sale there is no connection, the inventory throughout the supply chain is opaque and the information cannot be shared. Such not smooth logistics system will cause the reaction rate is lower and costs increase accordingly.

\subsection{The Logistics Information Management}

Logistics is that part of the supply chain which plans, implements and controls the efficient, effective forward and reverse flow and storage of goods, services and related information between the point of origin and the point of consumption in order to meet customer and legal requirements. Logistics information management is a unified planning and organization of logistics information resources, and controls logistics information collection, processing, storage, retrieval, transfer and application reasonably [1]. So that coordinated the logistics supply chain, achieved information shared and interaction, reduced information redundant and errors, assisted decision support, improved customer relationship, eventually realize a height unified in information, funds, business and logistics, and achieve the purpose of improving the competitiveness of supply chain of the logistics.

Quality logistics information platform means that the demand for logistics can enjoy faster, cheaper services, improve its efficiency or quality of life [2]. Than the public logistics information appears in form of platform mode, belonging to the portal of the logistics information

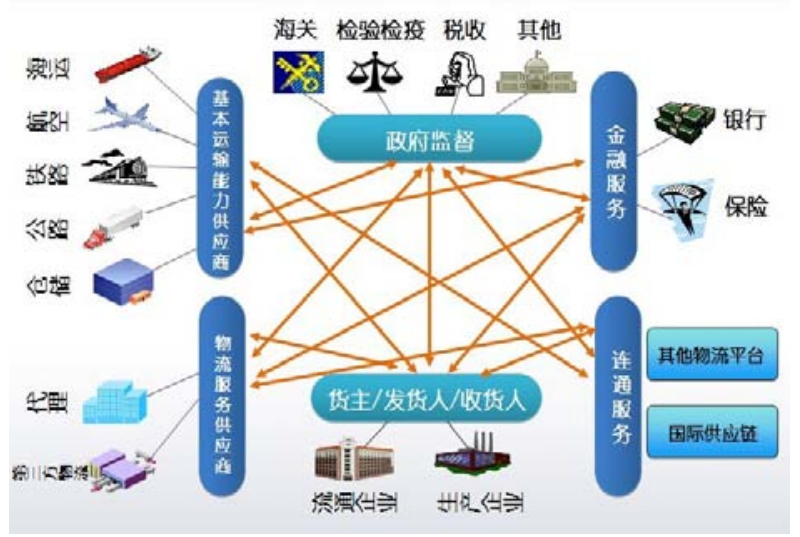


Figure 1. The traditional logistics model。

platform, it toward more diversity on the service scope and improves a greater scope of information exchange. The public logistics information has two different types of value trend; the one is the public information of a government-led investment, which is not for profit, and the other is the profitability corporate-led investment, there is a clear competition in the market. Figure 2 shows this kind of public logistics information platform.

The public information platform is to integrate the resources of the whole society so that the enterprises can achieve interconnection of information networks, can share the information resources to the society, can make full use of all resources in the areas of economic and social development, reduce operational costs and increase economic and social benefits.

\section{The Cloud Computing}

\subsection{The Theory of Cloud Computing}

Cloud Computing is the result of Distributed Computing, Parallel Computing and Grid Computing, which split the large calculating processing program into several small sub programs automatically by the network, finally the large amount of data which stored in distributed computer products work together with the processor resources so that the relevant calculation distribution in the distributed computer, rather than the local computer [3]. It's a business model provides the IT resources, data and application as a service to users through the network.

The goal of building cloud computing system is to move the independently, personal calculations which run on a PC or on a single server to a "cloud" server that have a huge number of data. This "cloud" server handles user requests, and output the results, it's a core system based on data computing and processing [3].

\subsection{The Architecture of Cloud Computing}

The architecture of cloud computing is divided into two parts of service and management.

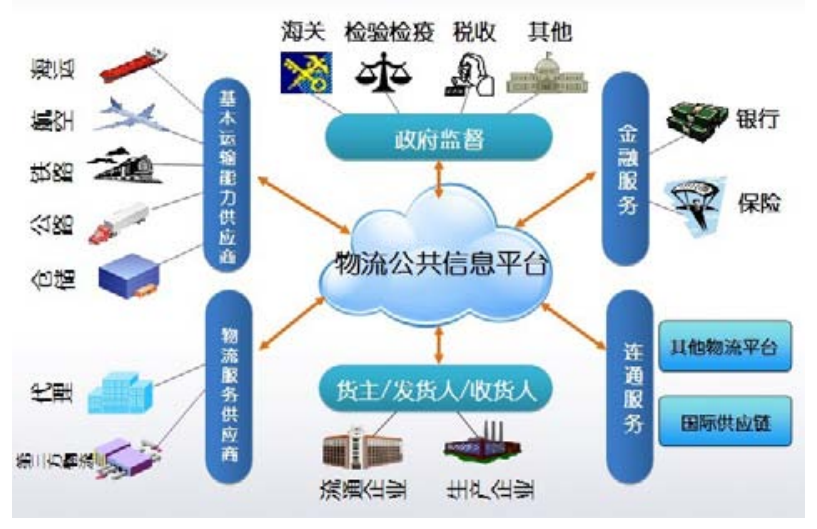

Figure 2. The public logistics information model.

- In service, it mainly provides all kinds of services based on cloud to users; it contains a total of three levels [4]. One is software as a service, or SaaS for shot, this layer provides the application to users with a web-based way; second is platform as a service, or PaaS for short, this layer provides the development and deployment of application as a service to users; the last layer is infrastructure as a service, or IaaS for short, it provides various elements of the underlying computing (such as virtual machine) and storage resources as a service to users. Form the user's point of view, this three services are independent, because of the services they provide are completely different, and different user-oriented. But from a technical point of view, these three layers have certain dependencies. For example, a SaaS products and services not only need to use SaaS layer technology, but also need the development and deployment platform provided by the PaaS layer or directly deploys on the computing resources provided by the IaaS layer, and the PaaS products and services is also likely to build above the IaaS layer services.

- In management, it mainly dominated by cloud management, its function is to ensure the entire cloud computing center to run security, stability, and can be effectively managed. Figure $\mathbf{3}$ is a display of the architecture of cloud computing.

\section{The Internet of Things}

\subsection{The theory of Internet of Things}

The internet of things, short for IOT, is a concept of network for information exchange and communication through extending or stretching its client to goods and goods on the basis of the internet [5], We can also understand this concept as through radio frequency identification (RFID), infrared sensors, global positioning systems, information sensing devices or other laser scanners agreed by the agreement, connected to the Internet to exchange information and communicate in order to achieve intelligent identification, location, tracking, monitoring, and management. Figure 4 shows the model of IOT.

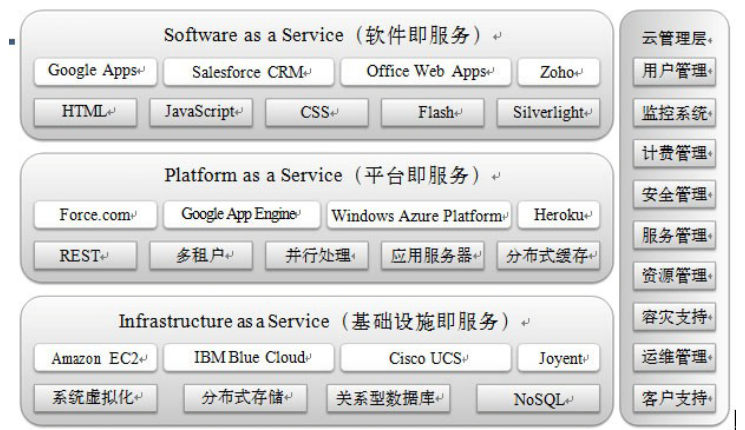


Figure 3. The architecture of cloud computing.

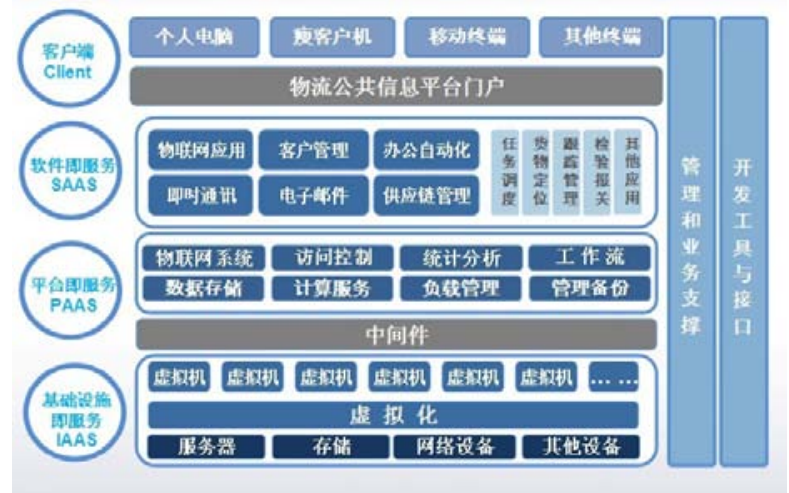

Figure 4. The model of IOT.

\subsection{The Characteristics of IOT}

The IOT has the mainly characteristics as follows:

- First, a comprehensive sense, namely uses of RFID, sensors, and QR code anytime, anywhere access to the information of objects.

- Second, reliable delivery, through the integration of various telecommunication and network, the information of objects can be delivered accurately at exact time.

- Third, intelligent processing, namely analyses and processing huge amount of data and information and controls the objects intelligently by using of cloud computing, fuzzy recognition and other smart technology.

\section{The Public Information Service Platform of Logistics}

\subsection{The Concept of the Public Information Service Platform of Logistics}

The public information service platform of logistics is innovation model of logistics information management. The platform relies on the technology of cloud computing and internet of things, with powerful data analysis, information exchange, mass storage, intelligent processing and other capacities, and combining the hyper-scale computing resources with the technology of RFID, QR code, GPS/GIS, mobile communication and 3G network to achieve efficiency, accurate, fast, and comprehensively management and improve the level of services in the logistics industry.

\subsection{The Principles of the Public Information Service Platform of Logistics}

- Firstly, establish a large-scale cloud computing resource center which is based on the architecture of cloud computing to achieve data exchange and unified management in all companies, organizations, institu- tions, departments, and ensure all types of logistics information response rapidly.

- Secondly, use the technology of IOT, take advantage of its technology of RFID [6], GPS /GIS, high speed internet to realize the information updated in real time, improve the operation and intelligent management, rich logistics operation management and improve business efficiency.

- Thirdly, establish standardization working procedures, namely deploy all kinds of generic software and IOT, etc., on cloud computing resource center to improve the capacity of data exchange, and personnel can through a unified interface for standardized operation and management with a clear division of labor [7]. These procedures can also monitor all logistics by using of the technology of IOT in time.

- Foully, take advantage of the technology of cloud computing and IOT above to build a public information platform of logistics which meet the business requirements [8]. Figure 5 shows the framework of the public information platform.

\subsection{The Advantages of the Public Information Platform of Logistics}

- Safe and reliable, it no longer depends on a variety of relative isolation of business systems, cloud computing model enabled centralized backup, fault tolerance, information management and guarantee the safe and reliable.

- Efficient, the information updates in real-time and interact with data, the coordination time can be greatly shortened, with the standardized operation and management, the system response time and efficiency have been improved.

- Centralized monitoring, the centralized information resource center make regulators easy to analyze data, manage information and watch business.

- Low price, the unified infrastructure management reduces IT management and maintenance; resources, on-demand, avoids waste of resources and improves the production efficiency and competitiveness.

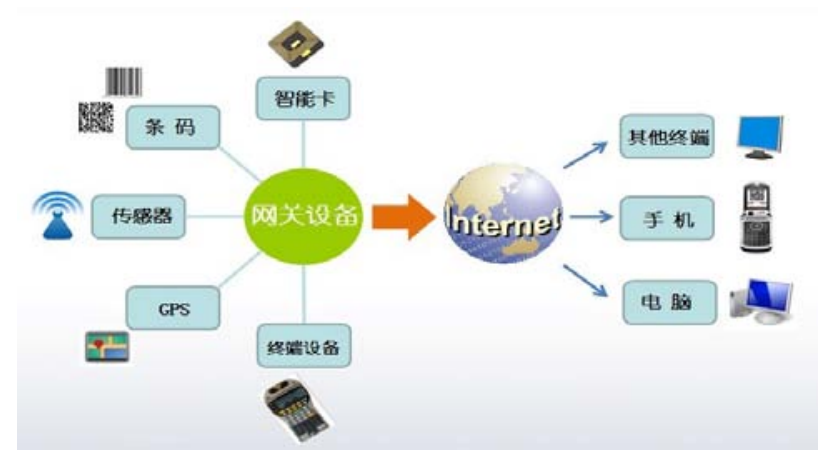


Figure 5. The public information service platform of logistics.

- Energy conservation, the unified large-scale infrastructure management center can reduce the accommodation and the engine equipment; the virtualized and cloud computing can increase resource utilization and reduce hardware purchases; the real-time information exchange avoids repetitive tasks and reduces staffing; the intelligent task scheduling make transport tasks integrated and the management of transport links intensive.

\subsection{The Significances of the Public Information Platform of Logistics}

- Promote the structure of the national economy, adjust and refine its structure.

- Promote the development of the internal division and specialization of the circulation industry; the efficiency of the emergence and development of logistics circulation can be also improved.

- Promote the rationalization of enterprises internal structures that enterprises can organize the logistics activities reasonably and meet the requirements of the market.

\section{Conclusion}

With the development of science and technology, making full use of scientific and technological knowledge for social development and contributing to mankind are the subjects of our freshmen. This article introduce the public information platform of logistics was built based on cloud computing and IOT, this platform can improve the efficiency of logistics circulation, and enterprises can organize the logistics activities reasonably, which can be reasonably use of resources, efficient logistics services and regional economic coordination and development.

\section{REFERENCES}

[1] H. G. wu and s. Dunn. Environmentally Responsisle Logistics Systerms[J]. International Journal of Physical and Logistics Management, 1995,25(2):20

[2] Jean-paul Rodrigue, Brian slack, Claude comtois. Green logistics[M]. Published in A. M. Brewer, K. J. Button and D.A.Hensher (eds), 2001:141-145.

[3] S. Gorniak, Cloud Computing, European Network and Information Security Agency (ENISA), 2009, Retrived:15.08.2010.

[4] Kelly Sims IBM introduces ready-to-use cloud computing collaboration services get clients started with cloud computing. 2007.

[5] Michael Chui, Markus Löffler, and Roger Roberts, The Internet of Things;

http://tc.indymedia.org/files/bigbrother/internet-spy-all.pd f

[6] Buckley, J. (2006). From RFID to the Internet of Things:Pervasive networked systems. In Report on the Conference organized by DG Information Society and Media,Networks and Communication Technologies Directorate,Brussels, March 6-7.

[7] M.Pappa, The Utility Business Model and Future of Computing services, IBM Systems Journal, 43,1,2004.

[8] Li XJ , Zhang M Y. Study on logistics information system architecture based on SOA. Logist Technol , 2007 , 26 (3) :104 